\title{
Germany, Estonia, Lithuania, Latvia: The Comparison of National Innovation Systems and the Change in Employment Structures
}

\author{
Artur Ivlevs \\ Faculty of Regional Economics and Economic Policy, Baltic International Academy, Latvia
}

Copyright (C) 2016 by authors, all rights reserved. Authors agree that this article remains permanently open access under the terms of the Creative Commons Attribution License 4.0 International License

\begin{abstract}
This article represents three points of view on the innovation development: the comparison of National Innovations Systems in Germany, Estonia, Lithuania, Latvia and the Measure the effectiveness of investments in the innovation sector. The third view is the confirmation of the thesis that the investment in the innovation sector changes the employment structures.
\end{abstract}

Keywords Innovation Mirror, Employment Structure, Investments in the Innovation Sector, Structural Changes, Sectors Theory

\section{Introduction}

Considering the political and economic conditions of development of NIS of Germany, the structure of scientific and research system of Germany, carrying out its analysis were made the conclusions that NIS of Germany can be used as a basis for building the NIS countries of the Baltic region. This conclusion was supported by the analysis of the geo-political information and history of development of Estonia, Lithuania and Latvia, political and economic conditions of development of NIS of these countries, structure of scientific and research system of the countries of the Baltic region.

In carrying out the comparative analysis of indicators of NIS of the countries of the Baltic region which is based on the comparison of individual indicators, it would be inappropriate to compare some absolute values without taking into the consideration the size of the country. However, if to stick to relative values, it is possible to identify the level of development of one or another innovation regional development. As in the scientific spheres there is no general consensus on the comparative methodology of NIS.

The carried out analysis of existing evaluation methods of economic growth on the basis of consideration of the level of innovative development of the country showed that in carrying out the analysis of the national innovation system should be taken into the consideration such indicators as human potential, investments in human capital, the quality of the educational system, the development of new technologies. As the secondary indicators should be considered the indicators that determine the direction of development of the political system, taking into the consideration the legislative changes, infrastructural development.

When calculating the indicators it should be taken into the consideration the influence of innovative development of the country on the implementation of structural changes in the economic system. The analysis of the level of innovative development according to the methodology suggested by the author of thesis research should begin with the analysis of costs for the researches and developments and carrying out of the following comparison with the other countries.

It should be calculated the level of costs for one researcher according to the analyzed countries in order to determine the level of financing of research sector.

At the next stage the author of the research suggests to consider the level of costs for researches and developments of sources of finances. The high share of costs of the business community for carrying out the researches and developments demonstrates the high level of development of the innovation system, when in the innovation processes is involved, not only the state, but also the private sector.

As the measurable results of innovation sector refer such factors as the number of patents, the number of innovation enterprises, as well as human capital.

The effectiveness of researches and developments is suggested to evaluate on the basis of determination of the number of scientific and technical articles (per 1000 personnel, involved in R\&D), the number of scientific and technical articles (per one million of population), the number of patent applications from residents and non-residents (per one million of population). 
The suggested methodology by the author of the research is based on the determination of the interrelation of structural changes and employment of the population by sectors. On the basis of the use of the statistical and analytical method, the introduced by the author the term "innovative mirror"[1] is proved within the frameworks of empirical observations.

Within the framework of the methodology the author of the research suggests to calculate a correlation coefficient, determining the interrelation of the level of costs for financing of innovation sector and number of involved employees in the innovation sector.
As another comparative unit is suggested to use the correlation coefficient, determining the dependence of the number of involved employees in the innovation sector and the number of employees in the primary sector.

\section{Materials and Methods}

At the first stage the author of the research thesis suggests a comparative analysis of the costs for researches and developments according to the analyzed countries (figure 1).

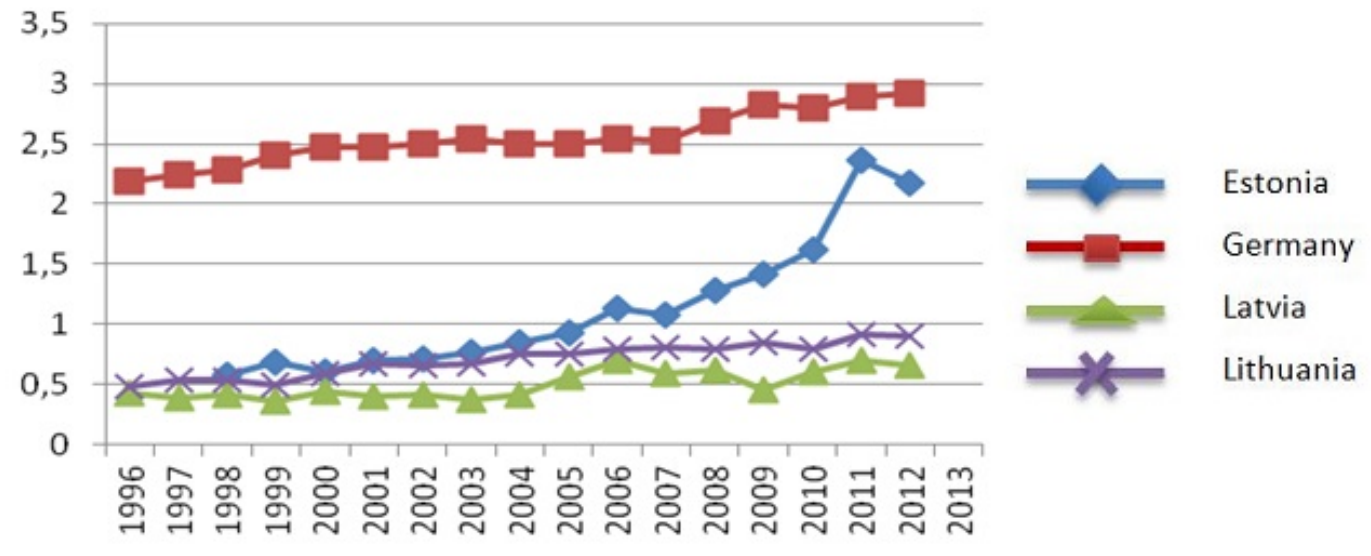

Source: UNESCO, access date 26.09.2014

Figure 1. Costs for researches and developments (\% of GDP)

The issue of financing of research activity is one of the main factors, influencing on the effectiveness of NIS and on the employment of working population of the region. A serious increase of financing of the research sector in recent years in carrying out the comparison of FRG, Estonia, Latvia and Lithuania is observed only in Estonia.

The costs per one researcher in Germany are 4 times higher than in Latvia and Lithuania and two times higher than in Estonia (figure 2).

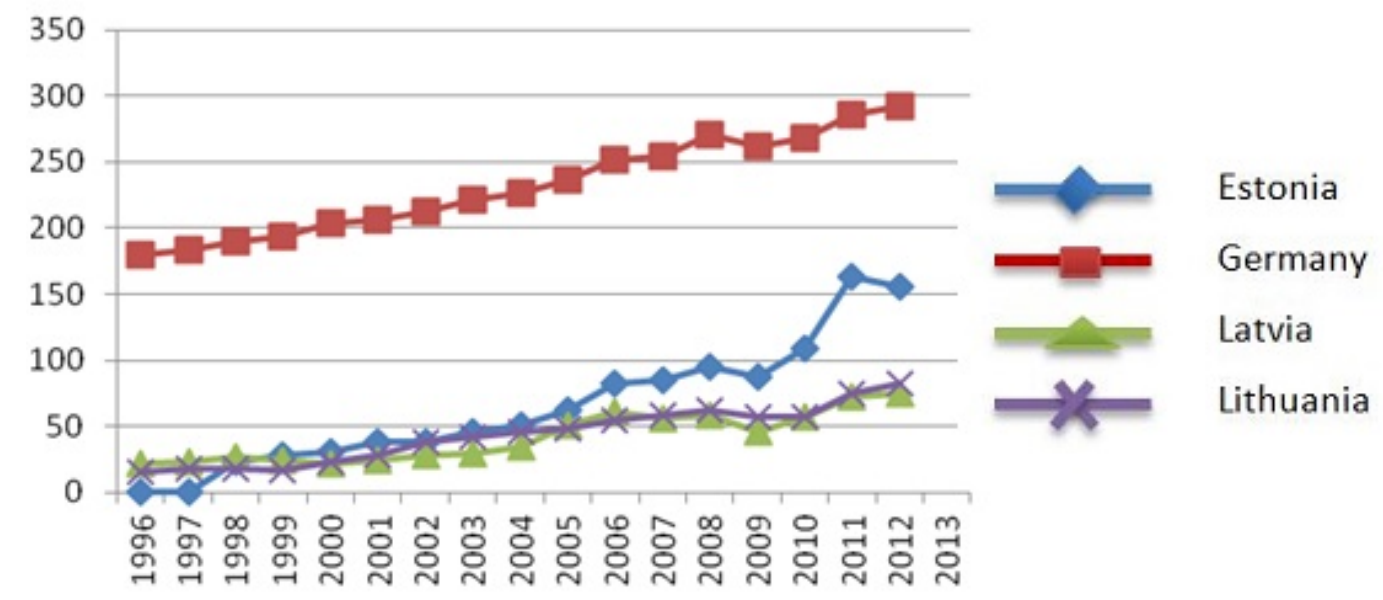

Source: UNESCO, access date 26.09.2014

Figure 2. The costs per one researcher (in thousand \$, at current)

At the next stage the author of the research suggests to consider the level of costs for researches and developments according to the sources of financing.

An interesting fact that is $62 \%$ of all costs for financing of research activity in Germany accounts for private sector. In Latvia and Lithuania this indicator makes up about $20 \%$ and in Estonia $48 \%$ (figure 3). 


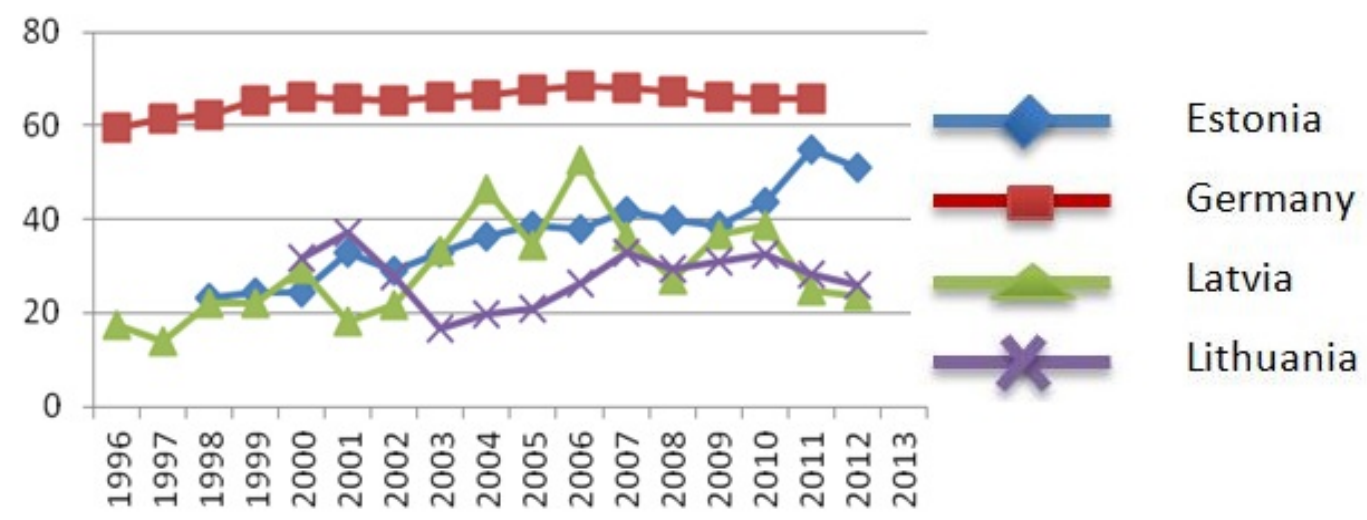

Source: UNESCO, access date 26.09.2014

Figure 3. Researches financed by business (\%)

Based upon the carried out observations and technical analysis, the jumps of the level of financing which are particularly pronounced in Latvia and Lithuania and less in Estonia is the result of recession of $2008-2013$.

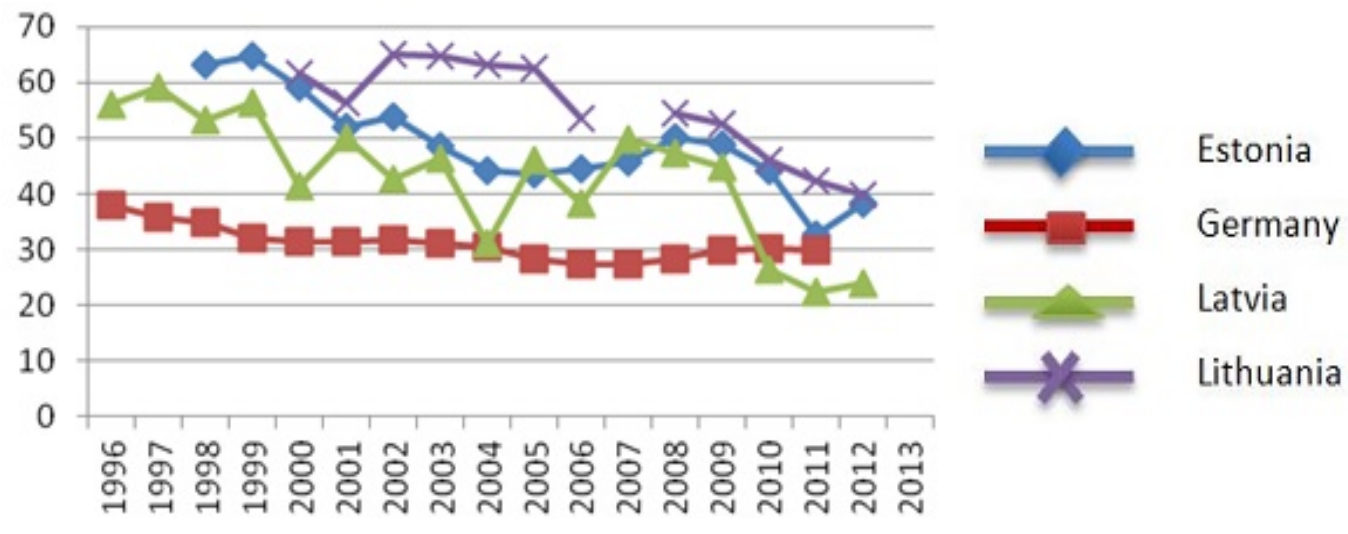

Source: UNESCO, access date 26.09.2014

Figure 4. The researches, financed by the state (\%)

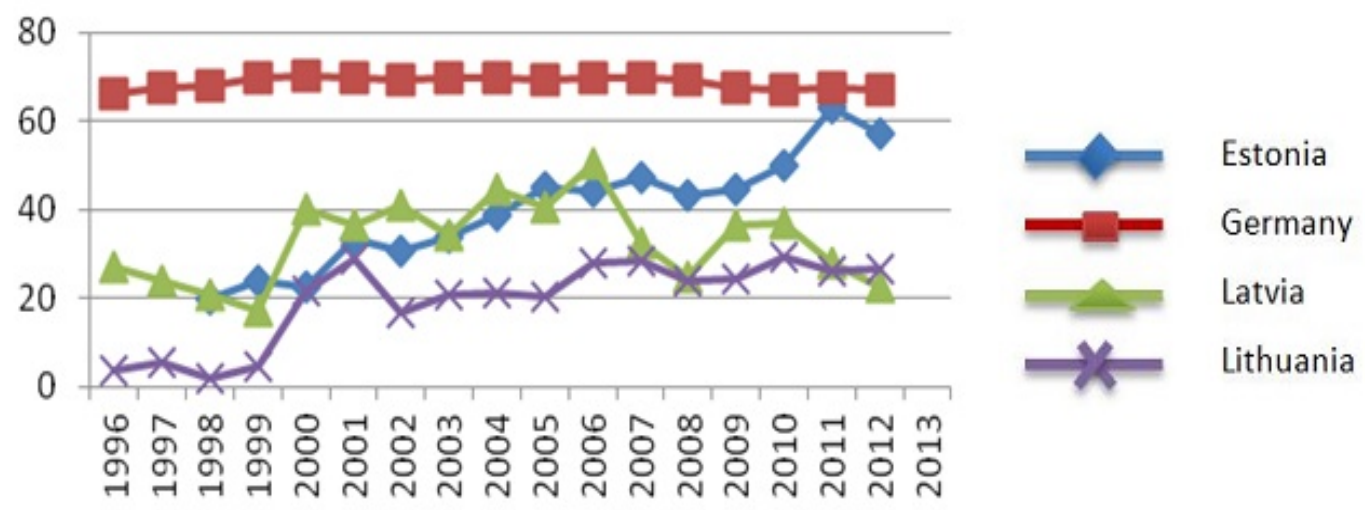

Source: UNESCO, access date 26.09.2014

Figure 5. The financing of researches and developments, implemented by the business -sector (\%)

In fact, figure 5 complements the carried out research and confirms the obtained results in the first part of this chapter during the establishment of structures of management of scientific and technological and innovation systems of Germany, Latvia, Lithuania and Estonia.

The financing of researches and developments, carried out by the sector of higher education in Latvia and Lithuania makes about 55\%, while in Germany the level of financing makes about 18\%. Estonia on this indicator is the closest to the German level. 


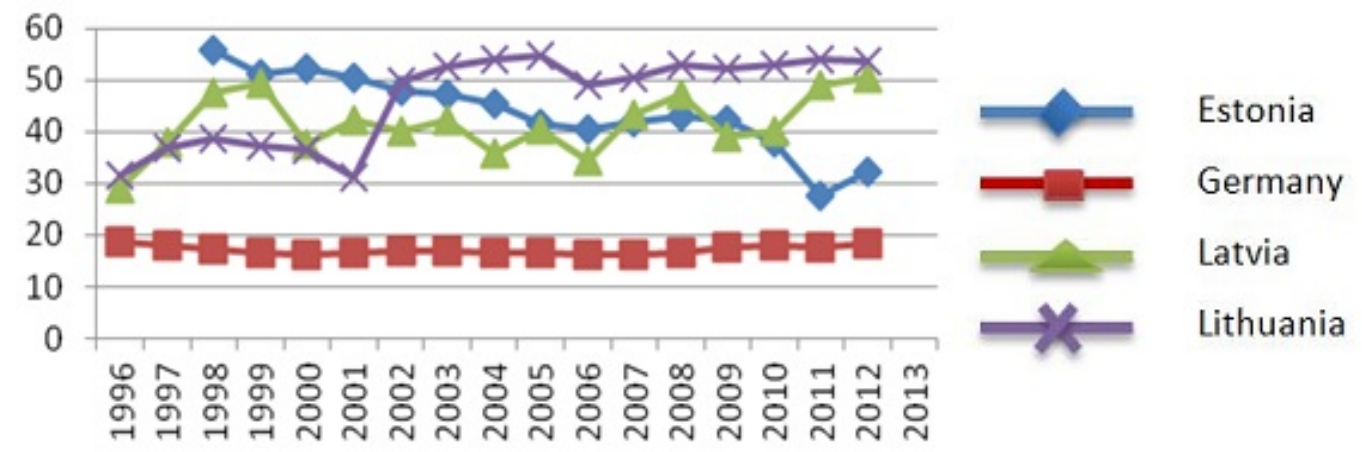

Source: UNESCO, access date 26.09.2014

Figure 6. Financing of researches and developments, carried out by the sector of higher education (\%)

It should be noted that it is quite difficult to carry out the evaluation of results of NIS and innovation sector by any analytical method. And many efforts made in recent years by the developing Baltic countries will bear fruits only through the years. However, despite this and for the purposes of this research, we will carry out the analysis of the status at the moment.

According to our opinion, to the measurable results of the innovation sector refer such factors as the number of patents, the number of innovation enterprises and etc. To these factors also refer the human capital.

The effectiveness of researches and developments $(R \& D)$ is evaluated on the basis of data, represented in Figures 7.

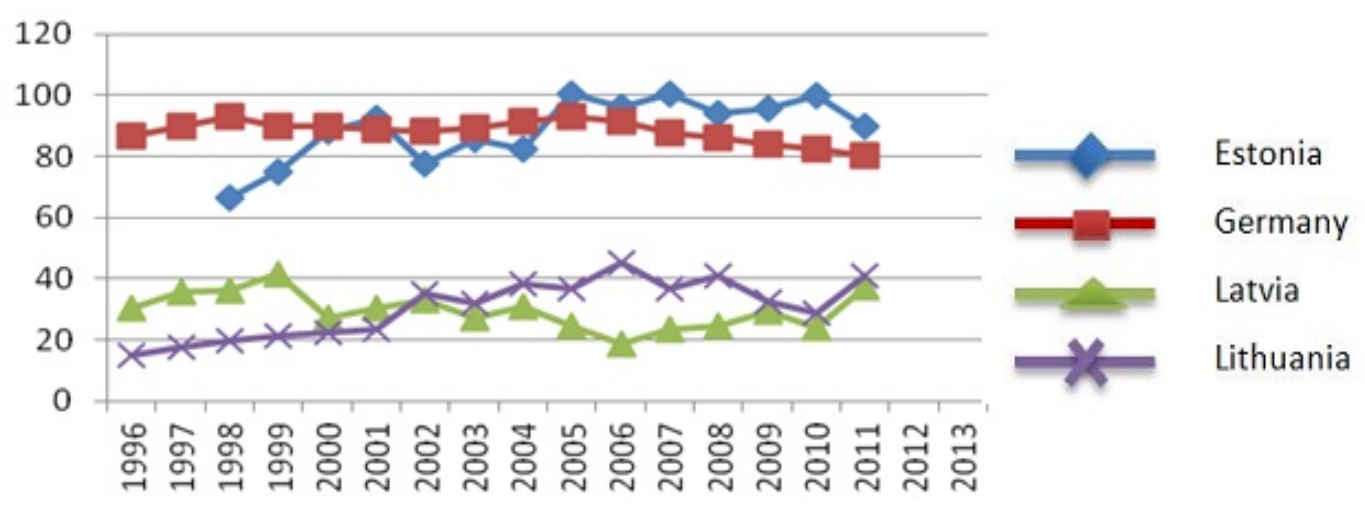

Source: UNESCO, access date 29.10.2014

Figure 7. The number of scientific and technical articles (per 1000 personnel, employed in R\&D).

Analyzing represented in the figure 7 data, it should be noted that the highest indicator on this criterion - in Estonia, as well as in FRG.

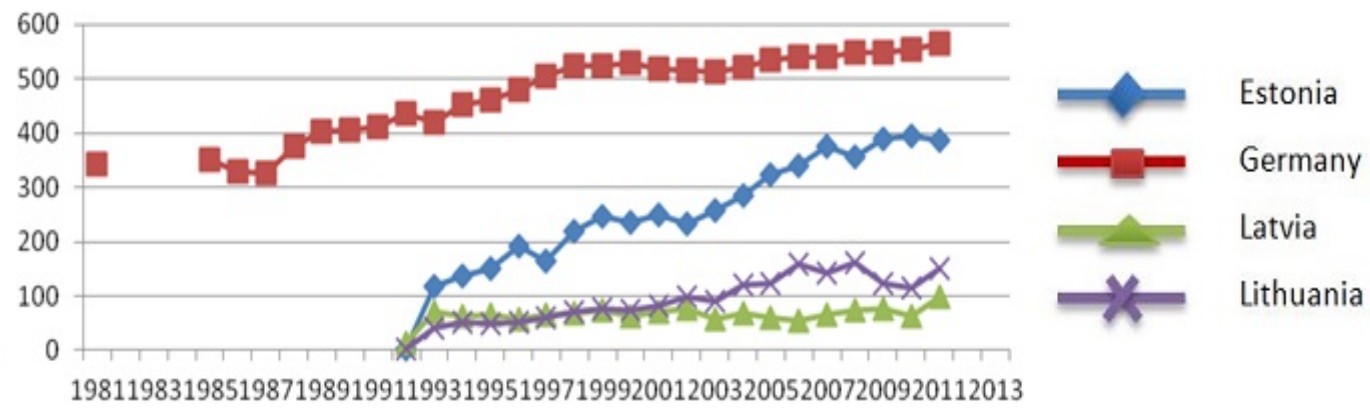

Source: UNESCO, access date 29.10.2014

Figure 8. The number of scientific and technical articles per million of population)

In carrying out the analysis of represented data in figure 8, it should be noted that according to this criterion, FRG exceeds the Baltic Sea States. 


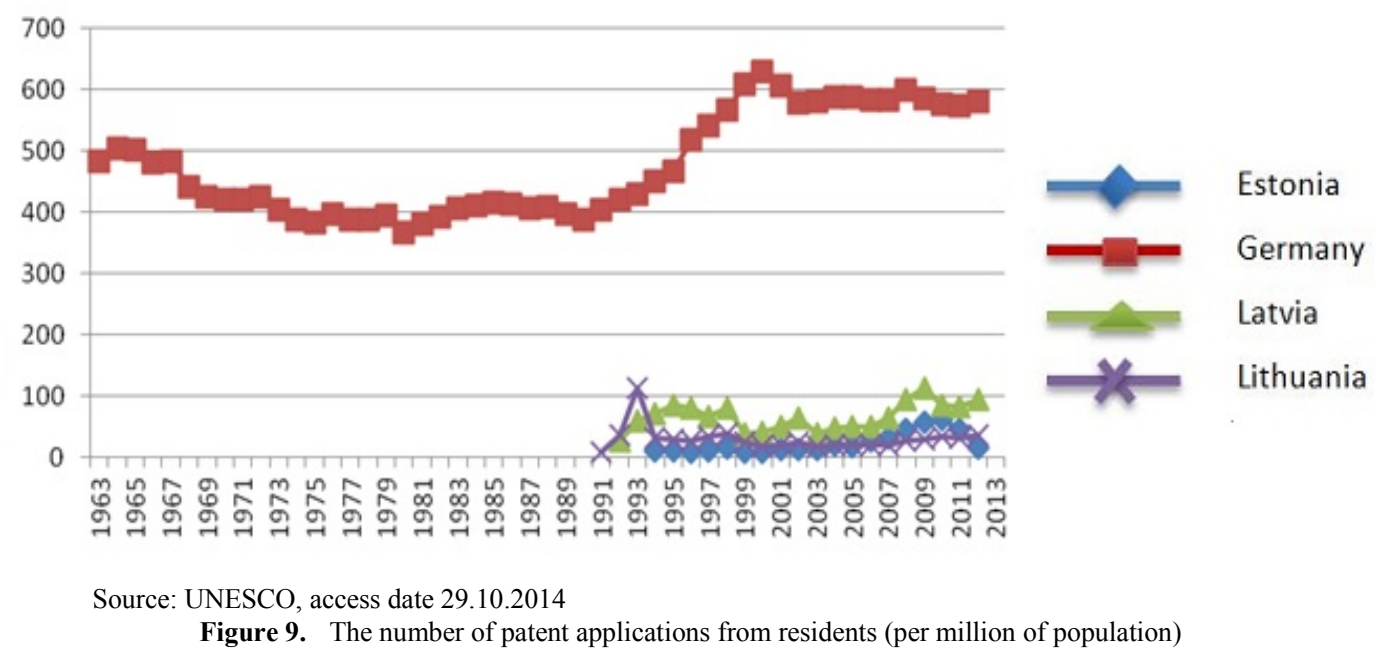

In FRG for the period from 2001 till 2013 this indicator makes about 600 applications that are $6-10$ times higher than the indicators of the Baltic Sea States.

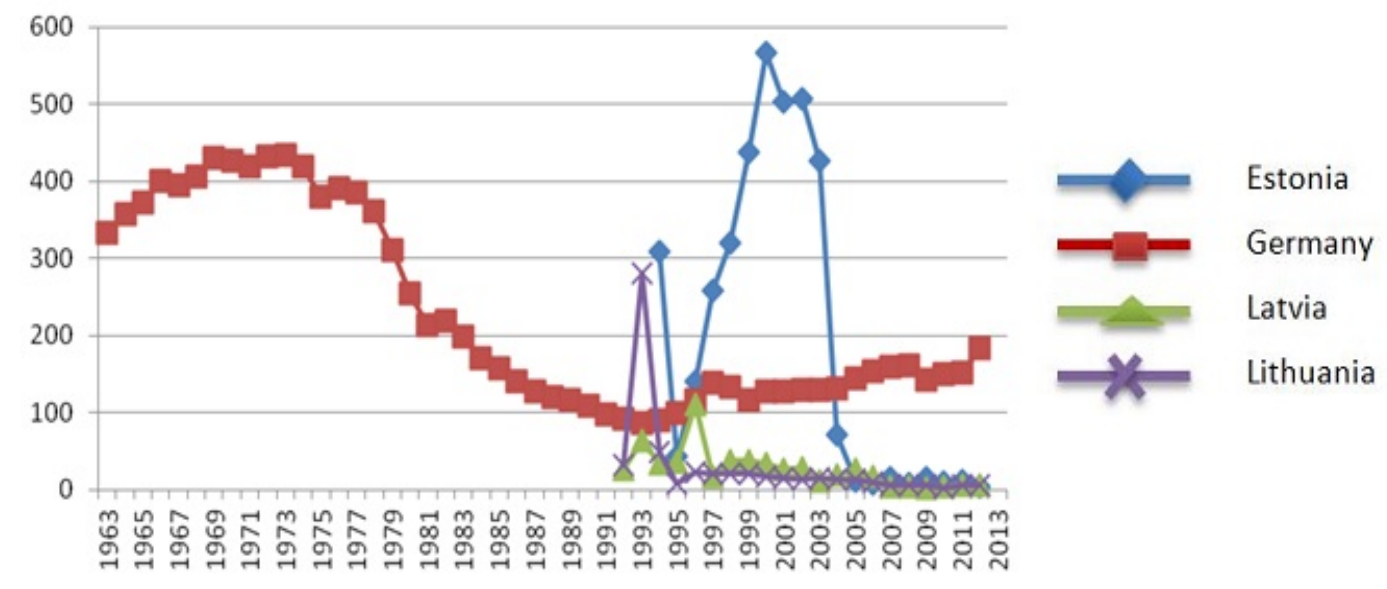

Source: WIPO, World Bank, access date 28.09.2014

Figure 10. The number of patent applications from non-residents (per million of population)

For the period from 1999 till 2004 according to this indicator the leadership kept Estonia. Beginning from 2005, in FRG the number of patent applications from non-residents makes about 200 units per million of population.

The predominance of private companies in the field of scientific researches and developments allows Germany more effectively to implement the development of the national science and innovations and be more competitive in a global perspective. On the matter, in particular evidence both the data of statistics on intellectual property (an absolute predominance of Germany over the Baltic States in number of patent applications from residents, acting patents, in number of trademark applications and acting trademarks) and data of global competitiveness indices and innovations in which Germany ranks among Top 20 countries (for comparison, the most successful of the Baltic States -
Estonia - only in the top 30) [2]. In the Baltic countries after 2005 the market of intellectual property is the less developed, unattractive for non -residents, especially after 2005 as evidenced by the decline of number of patent applications and active patents.

The author of the research suggests also considering the interrelation of structural changes and employment of population. The concepts of changes were described quite thoroughly in the first chapter. In this part of the paper, it should be shown, using the statistically analytical method that the introduced term "innovative mirror" by the author within the frameworks of empirical observations is provable.

First of all, let's consider the change of structure of employment of population. Figure 11 shows that the share of labor pool, employed in the primary sector is constantly declining. 


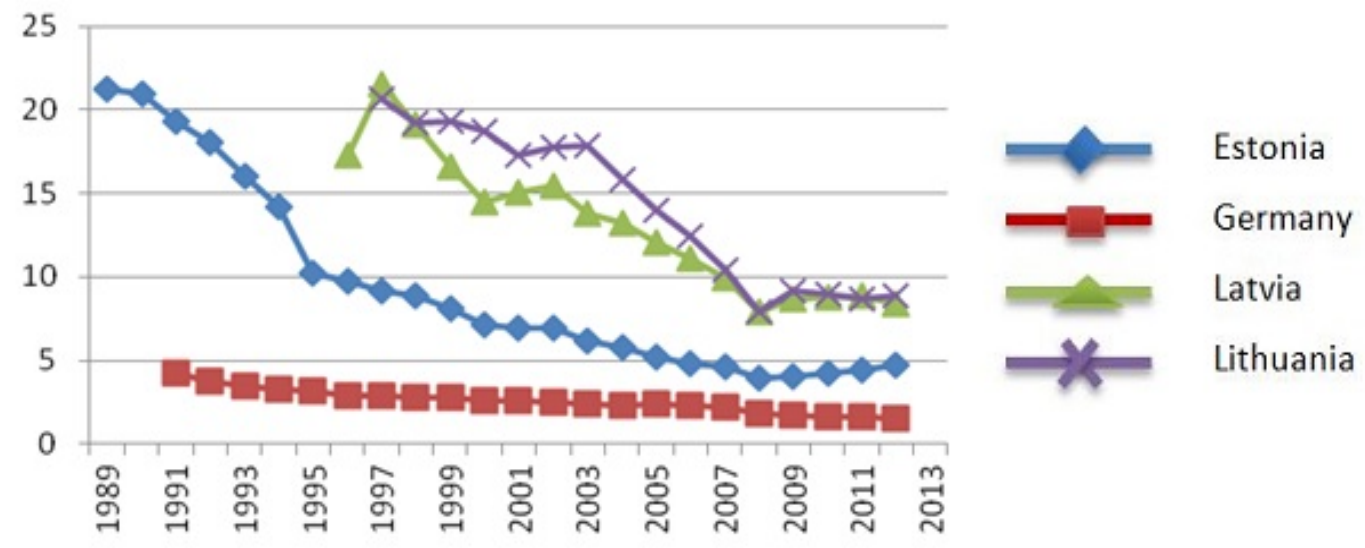

Source: WIPO, World Bank, access date 28.09.2014

Figure 11. Employment in agriculture (\% of full employment)

The number of labor force in the secondary i.e., industrial sector remains practically unchanged. These minor variations are depicted in Figure 12

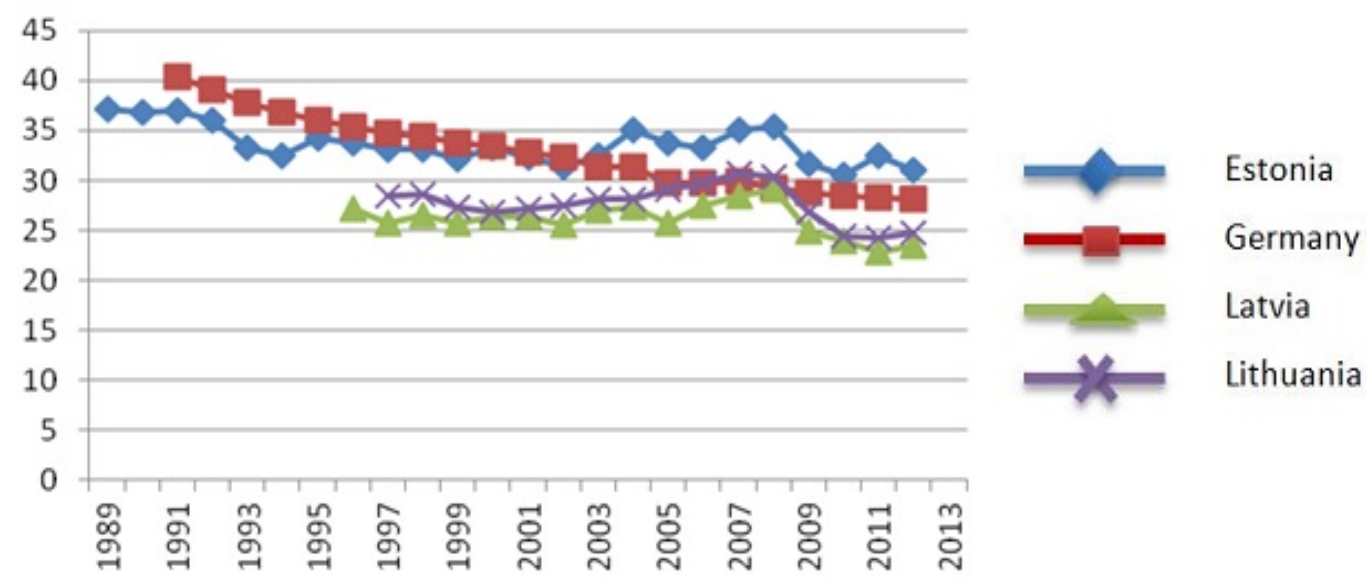

Source: WIPO, World Bank, access date 28.09.2014

Figure 12. Employment in the industry (\% of total employment)

The figure 13 shows the employment in the service sector. In all countries, it is possible to observe the increase of employment in the tertiary sector.

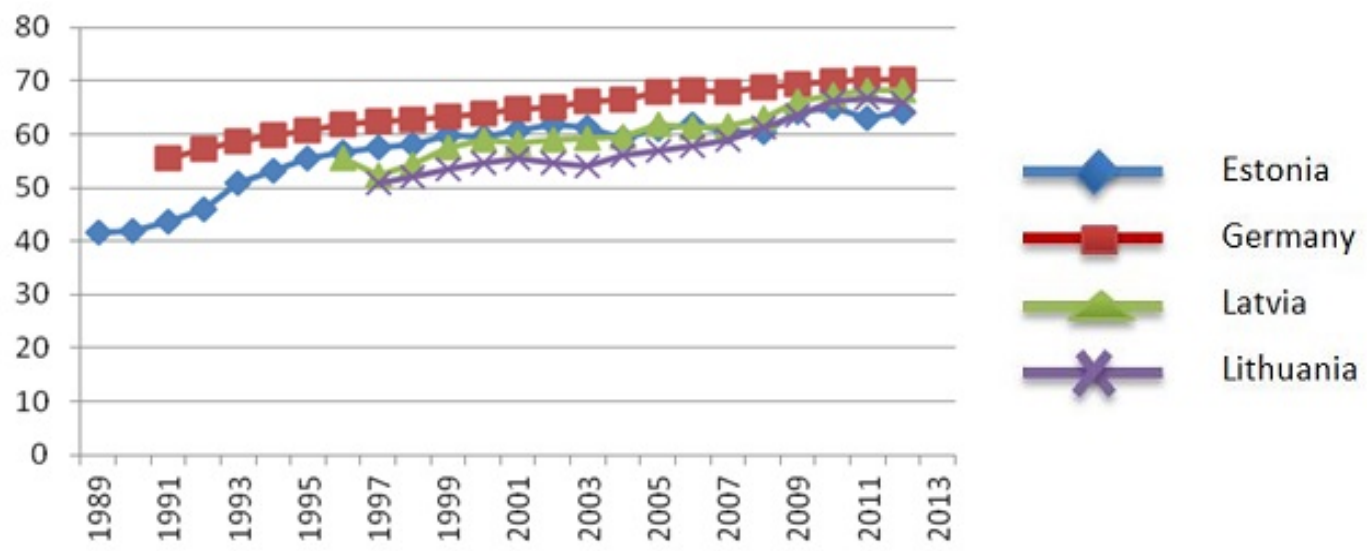

Source: WIPO, World Bank, access date 28.09.2014

Figure 13. Employment in the service sector (\% of total employment)

As for the number of researcher, then, their number in percentage terms grew the most impetuous in Estonia. 


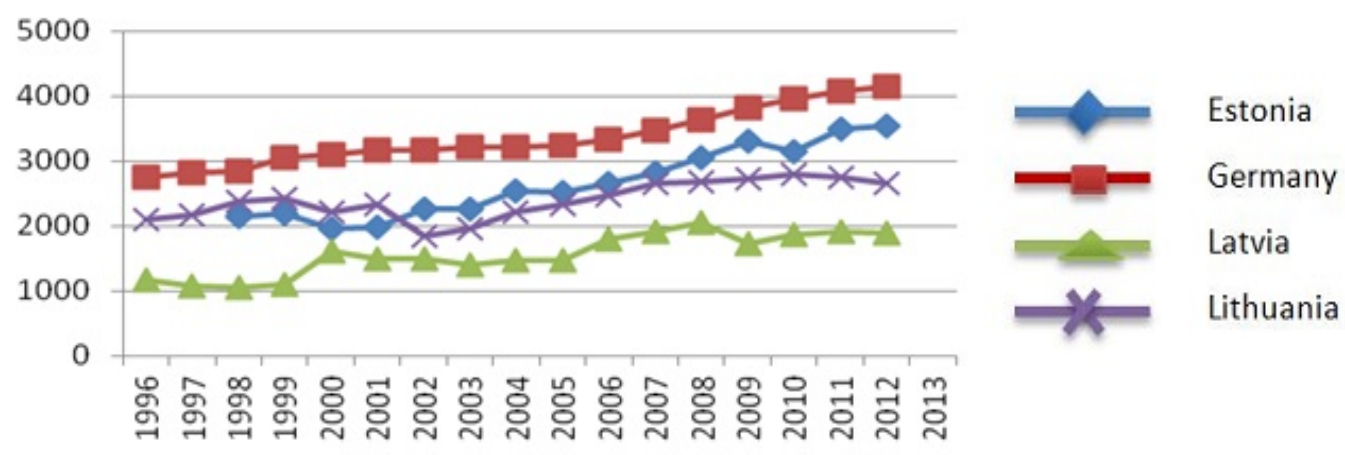

Source: UNESCO, access date 26.09.2014

Figure 14. The number of researchers, involved in the researches and developments (per million of population)

On the basis of the comparison method of statistical data, one may state that the increase of financing of scientific sector leads to the increase of number of employed employees in this sector. The technological progress releases employed individuals in the primary sector. Free human capital is used in the future in the high-technology industry. In fact, the circle closes. The reflection of innovation activity is the change of the structure of society - an innovative mirror reflects the investment level in the innovation sector and associated with this level the structural changes in society. From this term should be defined a derivative, namely, the level of efficiency of financing of innovation sector (LEFIS).

Comparing by the means of analytical method, we came to the following conclusion (table 1).

Table 1. The determination of correlation coefficient

\begin{tabular}{|l|l|l|l|l|}
\hline \multicolumn{1}{|c|}{$\begin{array}{c}\text { Correlation } \\
\text { coefficient }\end{array}$} & Estonia & Latvia & Lithuania & FRG \\
\hline $\begin{array}{l}\text { The financing of } \\
\text { innovation sector } \\
\text { and the number of } \\
\text { involved in the } \\
\text { employees in } \\
\text { innovation sector }\end{array}$ & 0,864 & 0,789 & 0,045 & 0,957 \\
\hline $\begin{array}{l}\text { The number of } \\
\text { involved in the } \\
\text { employees in thector } \\
\text { innovation sect } \\
\text { and number of } \\
\text { employees in the } \\
\text { primary sector }\end{array}$ & $-0,633$ & $-0,792$ & $-0,008$ & $-0,637$ \\
\hline
\end{tabular}

Source: the own calculations on the basis of DESTATIS data, access date 22.11.2014

The correlation coefficient for the financing of innovation sector and number of involved employees in the innovation sector shows the positive dynamics: in Germany and Estonia this coefficient is quite high. This means that the investments are used for the attraction of new employees. In Latvia this indicator is not so high, but in Lithuania it is relatively low. This conclusion is confirmed by the number of employees. In Lithuania, the number of employees is growing in comparison with Latvia, Estonia and Germany is the weakest.

The other comparative unit it is the correlation coefficient in the number of involved employees in the innovation sector and number of employees in the primary sector.

As expected, this correlation is negative. Lithuania shows the lowest correlation coefficient. However, as it was shown earlier on the basis of absolute values, a relatively small drift of labor into the research sector means the huge regional structural changes. For example, in Estonia the number of employees in research sector from 1991 till 2012 is increased by 1096 , while the number of employed people in the primary sector is reduced by 70.000 .

The principal difference in the structure of the quaternary sector (science, researches and developments, innovations) between Germany and the Baltic States lies in the fact that in FRG almost $70 \%$ of all R\&D are implemented and funded by the private sector.

Table 2. The analysis of innovation - active and innovative companies in the production according to the countries

\begin{tabular}{|c|c|c|}
\hline Country & $\begin{array}{c}\text { The percentage of } \\
\text { innovation - active } \\
\text { companies in the production }\end{array}$ & $\begin{array}{c}\text { The percentage of } \\
\text { innovative companies in } \\
\text { production }\end{array}$ \\
\hline Estonia & 53,759 & 48,862 \\
\hline FRG & 71,791 & 59,293 \\
\hline Latvia & 19,513 & 17,265 \\
\hline Lithuania & 22,207 & 20,223 \\
\hline
\end{tabular}

Source: own calculations on the basis of statistical data UNESCO and the EU, access date 26.09.2014

In the Baltic States this indicator is much lower. A certain exception here leaves Estonia $(50 \%$ of researches and developments is funded by the business), however, because of the small sizes of the country the increase of this indicator is provided due to the transition into the field of researches and developments just of a few companies.

Within the frameworks of the research is also suggested for the purpose of analysis of effectiveness of NIS of examined countries to make calculations of knowledge economy index - a complex index, characterizing the level of development of economy based on knowledge in countries and regions of the world. At the heart of the calculation of this index lie four key indicators:

1. The index of economic and institutional regime (The Economic Incentive and Institutional Regime). 
2. The index of education (Education and Human Resources).

3. The innovation index (The Innovation System).

4. The index of information and communication technologies (Information and Communication Technology - ICT).

The knowledge economy index is calculated as the average indicator in four abovementioned indices.

Also on the basis of three specified indicators (except the index of economic and institutional regime) is calculated such indicator, characterizing the level of development of NIS country as an index of knowledge (the calculation is also implemented on the basis of average value).

In the table 3 are represented data on the calculation of the knowledge economy index and index of knowledge according to analyzed countries. The used data in the calculation, taken from the annual report called "Global competitiveness 2013 - 2014"

Table 3. The calculation of the knowledge economy index and index of knowledge

\begin{tabular}{|c|c|c|c|c|}
\hline Indices & Estonia & Lithuania & Latvia & Germany \\
\hline I education & 0,859 & 0,877 & 0,813 & 0,884 \\
\hline $\begin{array}{c}\text { I economic and } \\
\text { institutional } \\
\text { regime }\end{array}$ & 4,7 & 4,5 & 4,5 & 5,5 \\
\hline I innovation & 51,5 & 41,0 & 44,8 & 56,0 \\
\hline I ICT & 7,68 & 6,74 & 7,03 & 7,90 \\
\hline $\begin{array}{c}\text { I economy of } \\
\text { knowledge }\end{array}$ & 16,18 & 13,28 & 14,29 & 17,57 \\
\hline I knowledge & 21,29 & 17,41 & 18,78 & 23,13 \\
\hline
\end{tabular}

Analyzing the data, represented in table 3 , it should be noted that Germany according to the analyzed two indicators is on the first place, on the second place - Estonia, Latvia is on the third place on the index of economy of knowledge, while on the index of knowledge the third place belongs to Lithuania.

\section{Conclusions}

On the basis of carried out research of national innovation systems of the Baltic Sea States on the methodology of the research suggested by the author was determined that the predominance of private companies in the field of scientific researches and developments allows Germany more effectively to implement the development of national science and innovations, to keep competitiveness in a global perspective. The confirmation of this serves the statistical data on intellectual property (an absolutely predominance of Germany over the Baltic States in the number of patent applications from non-residents, acting patents in the number of trademark applications and active trademarks), as well as data of global indices of competitiveness and innovations.

On the basis of analysis, carried out within the frameworks of the thesis research, it was determined that in Lithuania,
Latvia [3] and Estonia after 2005 was observed a low level of development of market of intellectual property and the confirmation of that is the decline of number of patent applications and active patents in the analyzed countries.

Within the frameworks of research is used the method of comparison of statistical data, confirming that the increase of financing of scientific sector leads to the increase of number of employed employees in this sector. As a result of technological progress the number of employed in the primary sector of the economy is decreased. At that is implemented the use of free human capital in hi-tech industries. In this regard, the author of the thesis research comes to the conclusion that as a reflection of the results of innovation activity, it should be considered the change of the structure of society. Consequently, the suggested concept of the innovative mirror of the thesis research is confirmed by the author. As a derivative, identified within the frameworks of concept of innovative mirror, the author of the research is suggest to consider the level of effectiveness of financing of innovation sector.

This indicator is analyzed, using the correlation coefficient, determining the level of dependence between the volumes of financing of innovation sector and number of involved employees in the innovation sector. The calculated ratio shows the positive dynamics: in Germany and Estonia this ratio is quite high. This indicates that the investments are used for the attraction of new employees. In Latvia[4] this indicator is not so high, but in Lithuania it is relatively low. This conclusion is confirmed by the number of employees. In Lithuania the number of employees grows in comparison with Latvia, Estonia and Germany is the weakest.

As another comparative unit acts the correlation coefficient, determining the interrelation between the numbers of involved employees in the innovation sector and number of employees involved in the primary sector. As a result of carried out calculations by the author of the thesis research, it was determined that this correlation is negative. Lithuania shows the lowest correlation coefficient. However, as it was shown earlier on the basis of absolute values a relatively small drift of labor in the research sector means huge regional structural changes.

Generally, for the Baltic States is typical the following trend: the main source of finance of researches and developments continues to be the public sector and funds from abroad (grants, funds within the frameworks of framework programs of the EU and etc.) and the main contractor acts the sector of higher school. In the terms of financing of researches and developments Germany is also the leader: if the share of financing of researches and developments in the total volume of GDP Estonia in many ways is able to come up with FRG in such indicator as financing of researches and developments in the terms of 1 researcher, Germany is still ahead of the Baltic States approximately twofold.

The scientific novelty of the research lies in the fact that on the basis of analysis of existing evaluation methods of economic growth, taking into the consideration the level of 
innovative development of the country the author of the research comes to the conclusion that as evaluation criteria of NIS should be used such indicators as human potential, investments in human capital, the quality of education system, the development of new technologies. To the group of secondary indicators refer the indicators, determining the directions of development of the political system, legislative changes, and infrastructural changes.

The author of the research suggests the analysis method of NIS, based on the determination of level of research and development costs and comparison with the other countries. The author of the research suggests calculating the level of costs per one researcher for analyzed countries in order to determine the level of financing of research sector.

The level of costs for researches and developments should also be determined by the sources of financing. The high share of investments on the part of private sector in researches and developments gives evidences of high level of development of NIS.

The author of the research suggests measuring the results of development of NIS on the basis of determination of number of patents, number of innovation enterprises. In this regard, the effectiveness of researches and developments, the author of the research suggest to evaluate on the basis of quantity determination of scientific and technical articles (per 1000 personnel, engaged in R\&D), the number of scientific and technical articles (per million of population), the number of patent applications from residents and non-residents (per million of population).

The determination of effectiveness of development of NIS of the country is suggested to implement on the basis of correlation coefficient, determining the interrelation of financial cost ratio of innovation sector and number of involved employees in innovation sector.

Besides, the author of the research suggests calculating the correlation coefficient, determining the dependence of number of involved employees in the innovation sector and number of employees in the primary sector.

The author of the research for the first time suggests the method of determination of interrelation of structural changes and employment of population in sectors.

"Innovative mirror" is a term introduced by the author of the research - parameterized, using the statistical and analytical method on the basis of data of empirical observations.

\section{REFERENCES}

[1] A. Ivlevs. Economic Annals - XXI. Structural changes in the state as a result of investment in innovative sectors. Kiev, 2014.

[2] A. Ivlevs. Management and Marketing: Experience and Problems. Innovation policy in Latvia. Minsk, 2014.

[3] A. Ivlevs. European Social Science Journal. Nr. 4. Innovation policy of Latvia in the Development Plan Latvia 2030. Critical View. Moscow, 2014.

[4] A. Ivlevs. IV International young researchers and students` scientific and practical conference. Nr. 4. Comparative Analysis of Innovation Policy in Latvia and Germany. Riga, 2014.

[5] DESTATIS data (Data base: https://www.destatis.de)

[6] World Economic Forum (data base: http://www.weforum.or $\mathrm{g} /$ )

[7] UNESCO (data base: http://en.unesco.org/WIPO)

[8] World Bank (data base: http://data.worldbank.org/) 